\title{
COMENTARIOS PARA MODERNIZAR EL RÉGIMEN DEL IMPUESTO GENERAL A LAS VENTAS EN EL PERÚ EN EL MARCO DE LA ECONOMÍA DIGITAL: LA EXPERIENCIA DE LA COMUNIDAD EUROPEA Y EL INMADURO RÉGIMEN PERUANO NOTES ON THE MODERNIZATION OF THE GENERAL SALES TAX REGIME IN PERU WITHIN THE FRAMEWORK OF THE DIGITAL ECONOMY: THE EXPERIENCE OF THE EUROPEAN COMMUNITY AND THE UNDERDEVELOPPED PERUVIAN REGIME
}

\author{
Rocío Zegarra Camarena* \\ Consultora independiente
}

This article approaches the treatment of ValueAdded Tax applicable to digital transactions in the European Union and Peru. In this regard, it is noted that, although Peru was one of the first jurisdictions in Latin America to face the challenges of digitalization of the economy in the field of Income Tax, over time these efforts have become outdated.

For this reason, after reviewing the main aspects and scope of the Peruvian Value-Added Tax and General Sales Tax regime, the author proposes some ideas to update them, based on the reflection of the European experience and its regulation on digital transactions.

KEYWORDS: Value-Added Tax; General Sales Tax; digital economy; digital age; digital transactions.
El presente artículo aborda el tratamiento del Impuesto al Valor Agregado aplicable a las transacciones digitales en la Unión Europa y en el Perú. En este sentido, notaremos que, si bien el Perú fue una de las primeras jurisdicciones en América Latina que intentó afrontar los desafíos de la digitalización de la economía en el ámbito del Impuesto a la Renta, con el paso del tiempo, este esfuerzo ha quedado desfasado.

Por esta razón, luego de revisar los principales aspectos y alcances del régimen del Impuesto al Valor Agregado y del Impuesto General a las Ventas peruano, se brindarán algunas ideas para actualizarlos sobre la base de la reflexión de la experiencia europea y su normativa aplicable a las transacciones digitales

PALABRAS CLAVE: Impuesto al Valor Agregado; Impuesto general a las Ventas; economía digital; era digital; transacciones digitales.

Abogada. Master of Laws (LL.M.) en Derecho Tributario Internacional por el King's College. Ex gerente sénior de Ernst \& Young. Consultora en ejercicio en Lima, Perú. Contacto: bedalli.zegarra_camarena@kcl.ac.uk.

Nota del editor: El presente artículo fue recibido por el Consejo Editorial de THËMIS-Revista de Derecho el 30 de noviembre de 2019, y aceptado por el mismo el 6 de febrero de 2020. 


\section{INTRODUCCIÓN}

La creciente digitalización de la economía ha cambiado sustancialmente los canales de producción, distribución y consumo de bienes y servicios (OCDE, 2019, p. 13). Tradicionalmente, un consumidor haría una compra en una tienda local, visitaría un agente de viajes, o llamaría un taxi por teléfono. Actualmente, el consumidor -por ejemplo- visita la página web o app de Amazon, Airbnb o Uber y con tan solo unos clics obtiene lo que busca, ya sea un producto, un alojamiento, o un taxi. Ello ha dado paso a que diversas empresas, sin poner un pie o un ladrillo en el territorio de un Estado, puedan participar activamente de su economía y generar innumerables ganancias desde un ordenador al otro lado del planeta. Claramente, este nuevo panorama económico ha desafiado el marco fiscal internacional con relación a los impuestos directos e indirectos (OCDE, 2015, pp. 12-13).

En cuanto al Impuesto a la Renta, existen diversas propuestas planteadas por la Organización para la Cooperación y el Desarrollo Económicos (en adelante, OCDE) y la Unión Europea (en adelante, UE) para gravar las rentas generadas por las Big-Techs en la jurisdicción donde se encuentran los usuarios de las plataformas digitales, independientemente del país de residencia de dichas entidades. Algunas de estas propuestas sugieren modificar el concepto tradicional de establecimiento permanente, introduciendo el concepto de presencia económica significativa o presencia digital significativa. Por otro lado, otras plantean crear gravámenes específicos, como el digital services tax, propuesto por la Unión Europea, que pretende gravar con 3\% los ingresos derivados por la prestación de ciertos servicios digitales a favor de usuarios establecidos dentro del territorio de la UE (Comisión Europea, 2018). Sin embargo, los fundamentos de estos cambios, así como el mejor método a seguir para gravar las rentas derivadas de las operaciones digitales, se encuentran en discusión y son controversiales. Por su parte, la OCDE ha indicado que emitirá su informe final al respecto en el 2020.

El Perú fue una de las primeras jurisdicciones en América Latina que ha intentado hacer frente a los desafíos de la digitalización de la economía en el ámbito del Impuesto a la Renta. En efecto, en el año 2003 se introdujo en la legislación del citado impuesto, la categoría de servicios digitales como un supuesto de renta de fuente peruana. Si bien el Perú se ha anticipado a otorgar un tratamiento a este tipo de rentas, será conveniente en su momento reevaluar la pertinencia de este régimen.

Por otro lado, con relación al Impuesto al Valor Agregado (en adelante, IVA) y el Impuesto General a las Ventas (en adelante, IGV), la UE fue la primera jurisdicción importante en incorporar reglas específicas para gravar los suministros en línea (Ivinson, 2004, p. 54). En efecto, la Sexta Directiva de la Unión Europea (en adelante, Sexta Directiva), en el artículo 58, incorporó el concepto de servicios prestados por vía electrónica (en adelante, SPE), con el objeto de sujetar a imposición en el país de destino aquellos suministros digitales prestados por empresas a favor de consumidores (en adelante, $\mathrm{B} 2 \mathrm{C})^{1}$. Al respecto, si bien las transacciones entre empresas (en adelante, B2B) siempre se gravaron en el país de destino, no ocurría lo mismo con las transacciones $\mathrm{B} 2 \mathrm{C}$, las que antes de dicha modificación solían estar sujetas al IVA en el país de origen (Ivinson, 2004, pp. 62-63).

Ahora bien, en materia del IGV, el Perú no ha contemplado en su legislación algún supuesto específico para sujetar a gravamen las transacciones realizadas en el ámbito de la economía digital; en específico, en lo referente a los servicios digitales prestados directamente a favor de consumidores por parte de entidades no domiciliadas en el país. En efecto, si bien las transacciones internacionales B2B están sujetas a imposición bajo el supuesto de utilización de servicios de no domiciliados, este no es el caso cuando se trata de servicios prestados en favor de consumidores, los cuales se encuentran fuera del ámbito de aplicación del IGV.

Por otro lado, cabe notar que en diciembre de 2014 se incorporó en la Ley del IGV el supuesto de importación de intangibles, en virtud del cual, parte de las transacciones digitales (adquisición de intangibles de no domiciliados) podrían estar sujetas a imposición en el país. Sin embargo, como veremos dicho régimen carece de aplicación práctica, pues no fue implementado con el objetivo de gravar las transacciones del entorno digital.

En este contexto, es importante destacar que la Comisión Económica para América Latina y el Caribe (en adelante, Cepal) subrayó la relevancia de incorporar reglas claras para gravar los suministros digitales en el campo de los impuestos al consumo (Cepal, 2019), especialmente teniendo en cuenta que, de no hacerlo, se estaría renunciando a acceder a recursos fiscales importantes. Al respecto, entre los países de la

\footnotetext{
Véase el artículo 58 de la Directiva 2006/112/EC, de 28 de noviembre de 2006, relativa al sistema común del impuesto al valor añadido.
} 
región que han incorporado en su legislación supuestos para gravar los servicios digitales con el IVA se encuentran los casos de Argentina, Colombia y Uruguay, mientras que Chile y México ya han presentado propuestas legislativas al respecto. Cabe destacar que, según Cepal², los ingresos por IVA que podría generar el Perú, sí es que este fuera aplicable a las transacciones digitales, ascienden a 34.6 millones de dólares americanos al año (2019, p. 78).

Más aun, en el mes de octubre de este año, representantes de la Administración Tributaria de la Superintendencia Nacional de Aduanas y de Administración Tributaria (en adelante, Sunat) indicaron a los medios de comunicación que están trabajando en una propuesta para sujetar con IGV las transacciones digitales B2C y que las entidades financieras serían las encargadas de retener el IGV y pagarlo al Fisco peruano.

En este contexto, este artículo pretende proporcionar una visión integral del tratamiento del IVA que se aplica a las transacciones digitales en la Unión Europea, como ejemplo de una regulación exitosa para gravar la economía digital, aunque no se encuentre libre de observaciones. A tal efecto, revisaremos los aspectos que conforman la hipótesis de incidencia del IVA con relación a las transacciones digitales y los mecanismos para su recaudación, así como las recientes modificaciones introducidas en el IVA al respecto. Para culminar este punto, brindaremos algunos comentarios y observaciones con relación al alcance y aplicación del IVA a las transacciones digitales en la UE.

En segundo lugar, revisaremos los alcances del IGV en el Perú y exploraremos algunas ideas para modernizar nuestra legislación, de modo que esta responda adecuadamente a las exigencias de la era digital. Específicamente, revisaremos los supuestos gravados actualmente con IGV, tales como la venta de bienes, prestación y utilización de servicios, e importación de bienes, y su aplicación a los modelos de negocio electrónicos, para finalmente brindar una lluvia de ideas en relación con aquellos aspectos que deberían modificarse en el marco de la economía digital.

Ahora bien, antes de abordar en profundidad los temas antes mencionados, es conveniente hacer una breve reseña de los modelos de negocio que operan en el mundo digital, así como repasar las características principales del IVA/IGV y los principios de política fiscal que deben inspirar la imposición de dicho tributo.

\section{MODELOS DE NEGOCIO EN LA ECONOMÍA DIGITAL}

Existen varias clasificaciones de los diferentes modelos de negocio que operan en la economía digital. Por ejemplo, Kofler, Mayr y Schlager (2018, p. 126) clasificaron las empresas digitalizadas en tres grupos según la intensidad en que estas dependían de la recopilación y explotación de datos personales.

A. Negocios tradicionales de ventas o servicios a distancia que se han desarrollado aún más debido a la digitalización.

\section{amazon}

\section{NETFLIX}

B. Híbrido: plataformas de múltiples aspectos que dependen de la contribución de datos del usuario junto con nuevos elementos digitales

\section{Q airbnb Booking.com}

\section{Uber}

C. Empresas basadas en la recopilación y explotación de datos personales.

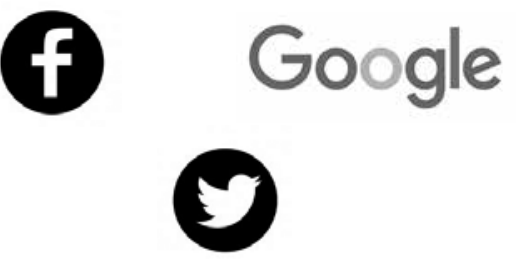

En opinión de Kofler, Mayr y Schlager, solo el grupo C (empresas basadas en la recopilación de datos personales) representa la esencia de la economía digital, mientras que los minoristas (por ejemplo, tiendas de aplicaciones, como Apple) y algunas plataformas que sirven de intermediarios dentro de los grupos A y B que usan internet para facilitar

2 Dicha estimación ha sido efectuada considerando las ventas de algunas compañías digitales con presencia importante en el país. Estas compañías son Netflix, Spotify, Uber y Apple. 
sus transacciones son únicamente extensiones de la economía tradicional que se han expandido debido a la tecnología de la información (2018, p. 126).

Por otro lado, Schön considera que los modelos de negocio como Amazon retail, Netflix, Microsoft, Apple, entre otros, se mantienen dentro del modelo tradicional de la relación bipartita: el proveedor y el cliente. Por el contrario, desde su perspectiva, otros modelos tales como Facebook y Google gestionan una relación tripolar, entre: (i) los usuarios de las plataformas; (ii) terceras empresas que pagan por los datos o publicidad dirigida; y (iii) el proveedor, es decir, las plataformas digitales (2018, p. 282).

A este respecto, la Comisión Europea (2018, p. 15) ha distinguido los modelos de negocio en cuatro categorías: modelo publicitario, servicios intermediarios, acceso a contenido digital y comercio electrónico, conforme describimos a continuación.

\section{A. Modelo publicitario}

De acuerdo con la Comisión Europea, este modelo involucra la prestación de dos servicios (2018, p. 15). Por un lado, se encuentra el ofrecer servicios digitales gratuitos a los usuarios a cambio del derecho a recopilar y procesar sus datos personales. Los servicios que ofrecen las plataformas son el acceso a redes sociales, email, sistema de búsqueda, almacenamiento de información, entre otros. De otro lado, tenemos el monetizar los datos de los usuarios vendiéndolos o prestando servicios de publicidad dirigida. Facebook, Google, Twitter, Instagram, YouTube, entre otros, formarían parte de este grupo.

\section{B. Servicios de intermediación (interfaces digi- tales multifacéticas)}

De acuerdo con la Comisión Europea, este modelo implica normalmente la prestación de dos servicios: (i) acceso a la plataforma digital a cambio de que los usuarios paguen una retribución, que podría ser un fee fijo (pago por suscripción o mensualidad) o un fee por cada transacción que se realice; y, (ii) la transacción subyacente: la plataforma permite a los usuarios localizar a otros usuarios e interactuar con ellos. En virtud de dicha interacción, la plataforma facilita la entrega de bienes o la prestación de servicios subyacentes directamente entre los usuarios, normalmente a cambio de una retribución (2018, p. 15). Sin embargo, en algunos modelos de negocio no se ofrece ningún servicio o prestación subyacente y el fee pagado únicamente otorga derecho a gozar de los beneficios o propiedades de la plataforma digital. Algunas plataformas que ofrecen servicios intermediarios son Amazon Marketplace (no retail), eBay, Airbnb, Uber, entre otros.

\section{Acceso a contenido digital / soluciones digi- tales}

Según la Comisión Europea, estos modelos de negocios otorgan acceso a plataformas digitales en las cuales los usuarios pueden descargar contenido digital o soluciones digitales (software) a cambio de una retribución (2018, p. 15). Por ejemplo, esto incluye cloud computing, software (Microsoft, Apple), vídeo (Netflix), música (Spotify), entre otros bienes intangibles.

\section{Comercio electrónico (venta a distancia)}

De acuerdo con la Comisión Europea, corresponde a la venta de productos que se ordenan en línea y se envían físicamente (2018, p. 15). Es importante destacar que el $57 \%$ del comercio electrónico de bienes se realiza a través de las tres más grandes plataformas digitales -Amazon, Alibaba e Ebay-, el $33 \%$ a través de vendedores directos y solo el $10 \%$ a través de otras plataformas (OCDE, 2019, p. 14).

Indudablemente la economía digital representa un fenómeno de alta complejidad, en que los modelos de negocio están en constante evolución y crecimiento. Lamentablemente, los sistemas tributarios no gozan de ese dinamismo.

\section{ALCANCES GENERALES SOBRE EL IMPUESTO AL VALOR AGREGADO}

\section{A. Definición del Impuesto al Valor Agregado}

El IVA se ha definido como un impuesto al consumo, plurifásico, no acumulativo (Hargitai, 2001, pp. 11-14). Esta definición es aplicable tanto al IVA, en los términos previstos en la Sexta Directiva que regula su aplicación en la Unión Europea, como en las leyes peruanas que regulan el IGV.

Al respecto, el objetivo del IVA como impuesto al consumo es gravar los gastos realizados por los individuos (Terra y Kajus, 2008, p. 282). En efecto, el término consumo se refiere normalmente a la adquisición de bienes o servicios para uso personal o para satisfacción de los individuos (Schenk y Oldman, 2007, p. 1). Sin embargo, el IVA es aplicable independientemente del uso o consumo efectivo de un producto; por lo tanto, su uso real es irrelevante para evaluar la aplicación del IVA (Lamensch, 2015, p. 12).

Por otro lado, el IVA podría aplicarse en todas las etapas de la cadena de producción y comercialización de bienes y servicios -es decir, plurifásico- o en una sola fase al final de la cadena -es decir, monofásico. EI IVA en la UE se ha estructurado como un impuesto plurifásico que se aplica cada vez que 
ocurre una transacción en relación con bienes o servicios sujetos al citado gravamen, incluidas las transacciones entre proveedores (Lamensch, 2015, p. 12).

Para complementar, el IVA es un impuesto no acumulativo. Esta característica implica que, para evitar el efecto en cascada de un impuesto de varias etapas, los sujetos pasivos pueden deducir el crédito fiscal derivado de las transacciones anteriores, de modo que el impuesto grava solo el valor añadido en cada etapa del proceso de fabricación y producción de los bienes y servicios (Lamensch, 2015, p. 14).

\section{B. Territorialidad del IVA}

En este campo corresponde determinar qué jurisdicción tiene derecho a imponer impuestos sobre rentas, ingresos o transacciones es de suma relevancia. Al respecto, el IVA podría aplicarse, por un lado, en el país de origen (lugar de producción) o, por otro lado, donde ocurre el consumo (país de destino).

Cabe destacar que el principio de destino es una consecuencia del carácter del IVA como impuesto al consumo, ya que este impuesto, en palabras de Hargitai "not only aims at taxing final consumption but also at taxing it at the place of consumption" ${ }^{3}$ (2001, p. 13). Más aún, para que el IVA tenga un carácter general, es necesario gravar todos los bienes y servicios independientemente de su origen, por lo tanto, correspondería que este se aplique a los suministros nacionales y a las importaciones (Terra \& Kajus, 2008, p. 290).

Al contrario, de acuerdo con el principio de origen, el país exportador mantiene la jurisdicción impositiva; por lo tanto, el IVA se aplica a los suministros y exportaciones nacionales, mientras que las importaciones no están sujetas a ningún cargo (Hargitai, 2001, p.14). La desventaja de un impuesto de origen es que la carga tributaria sobre los bienes importados y los bienes nacionales no sería la misma, y esta diferencia puede distorsionar la competencia, especialmente si los bienes provienen de una jurisdicción de baja carga impositiva (Terra \& Kajus, 2008, p. 291). Por otro lado, de acuerdo con Lamensch, el principio de destino "could maintain competitive neutrality between domestic supplies and imports, because the same tax system and, thus the same tax burden applies to both" ${ }^{4}(2015$, p. 21).
Ahora bien, debido a la coexistencia de ambos métodos, podría surgir el problema de doble imposición. Sin embargo, en la medida en que el principio de destino goza de consenso internacional, dicho problema no debiera presentarse con frecuencia o en gran intensidad (Terra \& Kajus, 2008, p. 290).

\section{Principios de política fiscal}

El Marco Tributario reconocido en la Conferencia de Ottawa realizada en octubre de 1998 ha establecido los principios de política fiscal que deberían seguirse al momento de regular el tratamiento tributario aplicable al comercio electrónico. Estos son los siguientes.

\section{Neutralidad}

"La tributación fiscal debería tratar de ser neutral y equitativa entre las formas del comercio electrónico y entre [e]ste y el comercio convencional, evitando así la doble imposición o la no tributación involuntaria" (OCDE, 1998, p. 3). En efecto, las decisiones de negocio deben motivarse por razones económicas y no en consideraciones de índole tributario (OCDE, 2017, p. 18).

\section{Eficiencia}

Se debería reducir al máximo los costos administrativos para los contribuyentes y para las autoridades fiscales.

\section{Certeza y simplicidad}

Las reglas fiscales deberían ser claras y fáciles de entender, de modo que los contribuyentes puedan anticipar las consecuencias fiscales de sus transacciones, de modo que se incluya cuánto, cuándo, dónde y cómo tributar.

\section{Efectividad y justicia}

La tributación fiscal deberá generar la cantidad justa de impuestos en el momento adecuado, reduciendo al mínimo las posibilidades de evasión fiscal.

\section{Flexibilidad}

Los sistemas tributarios deberían ser flexibles y dinámicos para que puedan ir en conjunto con los avances tecnológicos y comerciales.

No solo apunta a gravar el consumo final, sino también gravar el consumo [traducción libre].

4 Podría mantener la neutralidad competitiva entre las importaciones y las entregas nacionales, porque el mismo sistema tributario y, por lo tanto, la misma carga fiscal se aplica a ambos [traducción libre]. 


\section{REGULACIÓN DEL IMPUESTO AL VALOR AGREGADO SOBRE TRANSACCIONES DIGI- TALES EN LA UNIÓN EUROPEA}

A continuación, describiremos los aspectos de la hipótesis de incidencia tributaria previstos en la Sexta Directiva, que son relevantes para sujetar a gravamen las transacciones digitales en la Unión Europea. Tras ello, revisaremos brevemente los mecanismos de recaudación del IVA implementado en dicha jurisdicción.

\section{A. Aspecto subjetivo}

El contribuyente efectivo es el consumidor final, pues asume la carga económica del IVA, mientras que el sujeto pasivo es el que recibe los impuestos pagados por el consumidor y efectúa el pago del IVA correspondiente a la Administración tributaria (Pfeiffer, 2015, p. 176).

Por su parte, la Sexta Directiva en su artículo 9 (1) define al sujeto pasivo en términos amplios (Pfeiffer, 2015 , p. 177) y podría ser "cualquier persona, en cualquier parte del mundo, que realice actividades económicas (es decir, a título oneroso), y que no actúe como consumidor" (Terra \& Kajus, 2008, p. 367).

\section{B. Aspecto Material}

De acuerdo con el artículo 2(1) de la Sexta Directiva, una transacción debe cumplir dos condiciones para encontrarse gravada con el IVA: (i) calificar como entrega de bienes o prestación de servicios, y (ii) ser realizada a título oneroso. Las transacciones digitales se tratan a efectos del IVA de la misma manera que los suministros tradicionales de bienes o servicios (Lamensch, 2015 p. 164), por ende, también deben cumplir tales condiciones.

1. Primer elemento: entrega de bienes o prestación de servicios

La entrega de bienes se define en el artículo 14 (1) de la Sexta Directiva como "la transmisión del poder de disposición sobre un bien corporal con las facultades atribuidas a su propietario" (Directiva 2006/112/CE, 2006). Además, de acuerdo con el artículo 24 (1) "serán consideradas 'prestaciones de servicios' todas las operaciones que no constituyen una entrega de bienes" (Directiva 2006/112/ $C E, 2006)$. Esta definición residual de servicios deriva en que todas las actividades económicas se encuentren bajo el alcance del IVA, incluyendo también las transacciones relacionadas con intangibles (Lamensch, 2015 p. 75).
A partir de la distinción entre bienes y servicios, la citada directiva del IVA califica a los servicios prestados online como prestaciones de servicios bajo la categoría específica de SPE, en la medida en que los productos o servicios digitales no implican una transacción sobre bienes tangibles (Lamensch, 2015, pp. 72-73). Esta categorización de los suministros en línea tiene como objetivo gravar las transacciones B2C en el país de destino, mientras que el resto de los servicios B2C seguiría la regla estándar y estarían sujetos a impuestos en el país de origen ${ }^{5}$, salvo casos excepcionales como el de los servicios relacionados con propiedades inmuebles, entre otras.

La definición de SPE se puede encontrar en el artículo 7 del Reglamento del Consejo de la Unión Europea 282/2011 (en adelante, Reglamento del Consejo) que indica que estos servicios "abarcarán los servicios prestados a través de Internet o de una red electrónica que, por su naturaleza, estén básicamente automatizados y requieran una intervención humana mínima, y que no tengan viabilidad al margen de la tecnología de la información" (Reglamento de Ejecución de la Unión Europea 282/2011, 2011).

Adicionalmente, el Reglamento del Consejo -artículo 7 y anexo I- y la Sexta Directiva -anexo IIincluyen ejemplos no exhaustivos de lo que constituye o no SPE, como el suministro de productos digitalizados, incluido el software o sus actualizaciones, imágenes, textos, información, música, entre otros; la concesión del derecho a comercializar bienes o servicios en un mercado en línea, suministro y alojamiento de sitios informáticos, el mantenimiento a distancia de programas y equipos, enseñanza a distancia, entre otros.

Del mismo modo, el contenido intangible disponible en medios físicos ( $C D$, discos) no constituye SPE, así tampoco la reserva en línea de alojamiento, alquiler de automóviles, servicios de restaurante, transporte de pasajeros o servicios similares, ni la adquisición de bienes tangibles por vía electrónica.

En síntesis, para que un suministro califique como SPE debe cumplir las siguientes tres condiciones:

- $\quad$ Los servicios deben prestarse a través de internet o una red electrónica: esta condición excluye del alcance de SPE al suministro de bienes adquiridos a través de internet, pero entregados por medios físicos (Lamensch, 2015, p. 79).

\footnotetext{
5 Sobre este particular, se encuentran mayores alcances en el punto IV.C.
} 
- $\quad$ No son viables en ausencia de la tecnología de la información: este requisito está estrechamente relacionado con la condición mencionada anteriormente, ya que la tecnología de la información es la base del Internet (Lamensch, 2015, p. 81). En opinión de Lamensch (2015), la inclusión de esta condición tiene como objetivo confirmar que la tecnología de la información tiene un impacto no solo en la modalidad de prestación de los servicios sino también en su esencia. No obstante, Merkx no se encuentra de acuerdo, ya que, en su opinión, SPE "refers to services that are supplied electronically" 6 (2018, p. 17), es decir, solo el suministro del servicio debe ser automatizado, mas no el servicio en sí mismo, como se explica en el siguiente punto.

- $\quad$ Los servicios deben ser de naturaleza esencialmente automatizada e implicar una intervención humana mínima: este requisito debe determinarse teniendo en cuenta "the relationship between the supplier and the customer in relation to the supply in question only"7 (Merkx, 2018, p. 17). Siguiendo a Merkx, esto significa que las actividades administrativas que son necesarias para mantener los sistemas digitales, son irrelevantes para determinar si los servicios califican como SPE.

Además, según los documentos de trabajo del Comité del IVA y sus directrices, Merkx (2018) considera que no se cumple el requisito de intervención mínima cuando existe interacción o la posibilidad de interacción entre el proveedor y el cliente cuando los servicios se adaptan a los requerimientos del cliente y cuando los servicios se prestan al cliente mediante el envío de información por correo electrónico de manera no automatizada. Asimismo, de acuerdo con las Directrices del Comité del IVA, algunos ejemplos de servicios que no califican como SPE son los casos de casinos en vivo, donde los jugadores interactúan con un crupier; plataformas de astrología, donde el personal analiza la información para generar una respuesta; asesoramiento médico remoto, donde los profesionales analizan la condición del paciente.

Al respecto, Lamensch argumenta que únicamente el e-learning constituye SPE, mientras que las conferencias online en vivo no lo son, incluso si se brindan en un formato electrónico que no necesita intervención humana, es decir, mediante accesos en una página web (2015, p. 79). En su opinión, para calificar como SPE, no solo el modo en que el servicio es prestado debe ser automatizado, sino también su contenido (Lamensch, 2015, p. 79). Por otro lado, desde la perspectiva de Merkx (2018), este tratamiento es cuestionable, ya que implica que, si la conferencia se graba y se proporciona de manera automática, podría calificar como SPE. Merkx, en línea con el Comité del IVA, agrega que solo debería existir una diferencia en el tratamiento tributario aplicable a la enseñanza a distancia si, como parte de la conferencia en vivo, existe la posibilidad de interacción entre el cliente y el profesor (2018).

Adicionalmente, surgen interrogantes cuando existen varias prestaciones como parte de un servicio, y una de las prestaciones requiere un alto nivel de intervención humana. Merkx plantea un ejemplo sobre los servicios de citas en línea en los cuales el cliente además recibe algunos consejos (en este caso existen dos prestaciones a realizar, por un lado, acceder al servicio de citas, y por otro, proporcionar consejos) (2018). La pregunta gira en torno a si se trata de dos prestaciones distintas e independientes o se trata de una prestación única. En el primer caso, Merkx (2018) considera que el acceso a la plataforma de citas en línea calificaría como SPE y los consejos brindados no lo serían, en la medida que no son automatizados. En el caso de que se trate de una sola prestación, pero el asesoramiento es auxiliar al acceso al sitio web de citas en línea, el servicio calificará como SPE. Por el contrario, si el acceso en línea es auxiliar al asesoramiento y este califica como la operación principal, este no constituiría un SPE.

La discusión anterior resalta el hecho de que el alcance del concepto de SPE parece ser limitado y restrictivo (Lamensch, 2015, p. 79) y podría no abarcar toda la variedad de negocios digitales, lo que derivaría en que transacciones de similar naturaleza se encontrarían gravadas en diferentes lugares (SPE en el país de destino y no SPE en el país de origen).

Finalmente, cabe señalar que la adquisición de bienes tangibles por medios electrónicos, pero enviados de manera física, se encuentra excluida del alcance de SPE; pero la importación de dichos bienes sí se encontrará gravada con el IVA, bajo el supuesto general de importación de bienes.

Se refiere a servicios que se suministran electrónicamente [traducción libre].

7 La relación entre el proveedor y el cliente únicamente con relación al servicio a suministrar [traducción libre]. 


\section{Segundo elemento: onerosidad}

El Tribunal de Justicia de la Unión Europea (en adelante, TJUE) en Tolsma estableció que una transacción se realiza a título oneroso cuando existe un vínculo directo entre el servicio prestado y la retribución recibida. Además, en dicha decisión se indicó que la existencia de una relación jurídica entre el proveedor de la prestación y su destinatario "en cuyo marco se intercambian prestaciones recíprocas y la retribución percibida por quien efectúa la prestación, constituye el contravalor efectivo del servicio prestado al destinatario" (Sentencia del Tribunal de Justicia de la Unión Europea C-16/93/08, 1994).

En el caso Comisión c. República de Finlandia, el TJUE no encontró un vínculo directo suficiente entre los servicios de asistencia jurídica prestados y la retribución pagada por los clientes, en tanto que, primero, los honorarios de los servicios se determinaron en función de las circunstancias personales de los clientes y no por el valor real del servicio; y, segundo, pues la retribución acordada no cubría todos los costos incurridos por el proveedor (2009, pp. 48-51).

Una característica particular de algunos modelos de negocios digitales es que prestan servicios aparentemente de forma gratuita, pero en realidad reciben a cambio el derecho a utilizar los datos generados por sus usuarios (Pfeiffer, 2016, p. 158). Por ejemplo, Google proporciona acceso a servicios de correo, motores de búsqueda y otros servicios sin reclamar una contraprestación monetaria, ya que su interés es recopilar datos, sean datos personales o preferencias de búsqueda de los individuos, localización, entre otros, que luego monetizarán mediante publicidad dirigida o venta de macrodatos. Esto genera la pregunta sobre si este pago en especie califica como contraprestación para efectos de IVA desde la perspectiva adoptada por el TJUE.

A este respecto, algunos expertos consideran que la retribución no está dada por los datos obtenidos, sino por el derecho a acceder a dicha data y comercializarla. Desde esta perspectiva, sí podría existir una retribución por los servicios pactados (Pfeiffer, 2016, p. 160). Sin embargo, en la actualidad ningún estado miembro de la UE grava con IVA estos servicios.

\section{Aspecto espacial}

A fin de determinar el lugar en que se gravan las transacciones sujetas al impuesto, primero debe verificarse el status tributario de los clientes. Conforme al artículo 44 de la Sexta Directiva, si es- tos califican como un sujeto pasivo del impuesto (B2B), entonces se aplica el principio de destino y la transacción se gravará en la jurisdicción en donde este tenga la sede de su actividad económica. Mientras que si se trata de una transacción con una persona que no tiene la condición de sujeto pasivo -esto es, que califica como un consumidor-, según el artículo 45 de la Sexta Directiva, como regla general, el IVA se aplicará en el país de origen, es decir, en el lugar en que se encuentre la sede de la actividad económica del proveedor.

Ahora bien, existen ciertas reglas especiales que dependen de la naturaleza de las transacciones realizadas. En efecto, el artículo 58 de la Sexta Directiva establece una excepción en relación con los SPE prestados a favor de consumidores, los cuales se sujetan a una imposición en el país de destino, es decir, donde se encuentra establecido el clienteconsumidor, o donde este tenga su domicilio o residencia habitual.

Finalmente, cabe mencionar que la Sexta Directiva, en su artículo 59-A, también reconoce la utilización y explotación efectiva del servicio como un factor para determinar el lugar de imposición. Sin embargo, es una regla excepcional que solo se aplica a las transacciones que involucran jurisdicciones no pertenecientes a la UE y como prerrogativa para que los estados miembros eviten casos de doble imposición, no imposición o distorsión de la competencia.

Concluimos que, de acuerdo con dicha disposición, si en virtud de la aplicación de otras reglas que determinan el lugar de imposición del IVA este sería la UE, pero el uso y explotación efectiva están fuera del territorio de la UE.

Eentonces, el servicio se considerará recibido fuera del territorio de la Comunidad Europea y viceversa.

\section{Recaudación del Impuesto al Valor Agregado}

Las operaciones internacionales B2B se recaudan mediante el reverse-charge system (inversión del sujeto pasivo), el cual implica que la determinación del impuesto y su pago al fisco deben ser efectuados por el sujeto adquirente de los servicios en el país de destino.

Por otro lado, como se indica en la Sexta Directiva, artículos del 358 al 369, el mecanismo de recaudación aplicable a los servicios transfronterizos con consumidores que no tienen la condición de sujeto pasivo del impuesto (B2C), es el OSS (one-stop shop) o MOSS (mini one-stop shop) que aplica a proveedores de la UE como a no residentes en la UE. En virtud de este siste- 
ma, los proveedores deben registrarse y obtener un número de identificación para efectos del IVA en uno de los estados miembros de la UE de su elección, al cual deben reportar sus transacciones con consumidores de dicha jurisdicción. Este sistema es simplificado, pues no es necesario que los proveedores se registren en todos los estados miembros en que operan, sino solo en uno. La autoridad tributaria de dicho país se encargará de remitir los impuestos pagados bajo este sistema a los países miembros que corresponda (Lamensch, 2015, pp. 137-139).

\section{E. Paquete digital de modificaciones al Im- puesto al Valor Agregado}

Recientemente la Comisión Europea ha incorporado diversas modificaciones a la Sexta Directiva y al Reglamento del Consejo como parte de su estrategia para incentivar el mercado único digital europeo (Bal, 2019), algunas de las cuales entraron en vigencia el 1 de enero de 2019 y otras recién lo harán a partir del 2021. Este paquete consiste en una directiva y dos reglamentos de Consejo, cuyo objeto es asegurar la neutralidad del IVA y evitar la distorsión de la competencia.

De acuerdo con la propuesta elaborada por la Comisión Europea, las empresas europeas se encuentran en desventaja frente a aquellas empresas establecidas fuera de la UE. Ello pues estas, evadiendo el cumplimiento de las reglas establecidas en la Comunidad Europea, pueden fácilmente eludir el pago del IVA (Lamensch, 2017, pp. 137-146).

Por otro lado, el paquete digital tiene como fines, por un lado, reducir los costos administrativos, así como simplificar las reglas del IVA en relación con transacciones digitales; y por otro, asegurar la recaudación del citado impuesto. Las modificaciones introducidas son diversas y complejas. Sin embargo, a efectos de este artículo es importante mencionar las siguientes.

1. Modificación de las reglas de localización de servicios para pequeñas empresas

Las empresas establecidas en la Unión Europea que brinden SPE a consumidores finales únicamente estarán obligadas a tributar en el país de destino -es decir, donde se ubican los consumidores- cuando los ingresos correspondientes a dichos servicios superen el umbral a escala comunitaria de EUR 10,000 euros, conforme al nuevo artículo 58 (2-6) de la Sexta Directiva. El objetivo de esta modificación es facilitar el cumplimiento tributario, así como brindar la posibilidad a las pequeñas empresas de beneficiarse de los regímenes de excepción que se prevean en su país de origen (Bal, 2019).
2. Simplificación en las presunciones de ubicación del cliente

Como hemos mencionado en el punto IV.C, cuando se trata de SPE en favor de consumidores finales, estos se gravan en el país de destino. A tal efecto, es de suma relevancia determinar bajo qué circunstancias un consumidor se encuentra establecido, o tiene su domicilio o es residente habitual de la UE, a fin de determinar el lugar en que se encuentran gravados los SPE. Al respecto, la Resolución de Consejo establece en sus artículos 24 b y $24 f$ que el prestador del servicio presumirá que el cliente está establecido o tiene su domicilio o residencia habitual en el lugar en que se presenten dos elementos de prueba no contradictorios, que pueden ser los siguientes: la dirección de facturación del cliente; la dirección del protocolo internet del dispositivo utilizado por el cliente o cualquier sistema de geolocalización; los datos bancarios, como el lugar en que se encuentra la cuenta bancaria utilizada para el pago o la dirección de facturación del cliente; el código de móvil o la ubicación de la línea fija terrestre utilizada por el cliente; y otra información relevante desde el punto de vista comercial.

La verificación de estas condiciones por parte de los proveedores es compleja y no es claro cuál sería el camino a seguir si no se logran identificar dos elementos de prueba no contradictorios (Bal, 2019). En vista de ello, a partir del 1 de enero de 2019, respecto de transacciones intracomunitarias, únicamente se exige un elemento de prueba respecto de la ubicación del cliente, ello siempre que los ingresos del proveedor no superen los EUR 100,000 euros, según el nuevo artículo $24 \mathrm{~b}$ del Reglamento del Consejo. Sin embargo, esta simplificación únicamente aplica para proveedores de la Unión Europea, pues las condiciones mencionadas en el párrafo anterior se mantienen para proveedores que no son de la UE.

\section{Importación de bienes de menor valor}

Como hemos mencionado, la adquisición de bienes tangibles por medios electrónicos no califica como SPE. Sin embargo, la importación de dichos bienes se encuentra gravada como tal con el IVA. Ahora bien, actualmente los bienes de menor valor importados hacia el territorio de la UE, es decir, aquellos que no superen de EUR 10 a EUR 22 están exentos del IVA.

Al respecto, debido al crecimiento exponencial del comercio electrónico, los ingresos fiscales que se dejan de percibir debido a dicha exención también se han incrementado (Papis-Almansa, 2019). Además, según menciona Lamensch (2017), es de conocimiento general que muchos bienes son 
declarados como de menor valor cuando en realidad valen un precio más elevado. Finalmente, cabe destacar que la OCDE ha recomendado eliminar o reducir este tipo de exenciones a fin de que los ingresos derivados del comercio electrónico se encuentren sujetos al IVA (OCDE, 2015).

En atención a estas razones, esta exención ha sido suprimida y a partir del 01 de enero de 2021 todos los bienes -cualquiera sea su valor- se encontrarán sujetos al IVA. Dado el incremento de importaciones sujetas a gravamen, y a fin de simplificar la recaudación del IVA, se han previsto algunas modalidades diferentes para recaudar el impuesto, cuando se trata de bienes cuyo valor es menor a EUR 150 (Papis-Almansa, 2019). De forma novedosa, el nuevo artículo 14 de la Sexta Directiva señala que las plataformas digitales que faciliten la importación de bienes en el marco de una transacción B2C serán responsables del pago del IVA. En ese sentido, se asume que la plataforma ha adquirido los bienes importados del proveedor (B2B) y luego los ha vendido al consumidor final (Papis-Almansa, 2019).

\section{F. Breves observaciones y comentarios sobre la legislación del Impuesto al Valor Agrega- do en materia de servicios digitales}

1. Sobre su calificación como servicios electrónicos

Los SPE deben ser automatizados y deben requerir mínima intervención humana a fin de calificar como tales. Esta condición ha sido criticada ya que restringiría el alcance de aplicación de dicho régimen y podría excluir servicios que, no siendo automatizados, sí se prestan de forma remota, mediante la tecnología de la información.

Por esta razón, Merkx sugiere modificar la definición de SPE para eliminar el factor de intervención humana. La propuesta de definición de SPE que dicha autora plantea es la siguiente:

Electronically supplied services as referred to in Directive 2006/112/EC shall include services which are delivered over the Internet or an electronic network, where the supplier and recipient of the service due to the digital nature of the service can be located in different places and which are impossible to ensure in the absence of information technology $(2018, \text { p. } 21)^{8}$
Por otro lado, Lamensch va más allá y recomienda eliminar el concepto de SPE y crear una categoría de suministros de intangibles, la cual incluiría servicios que se presten o entreguen de forma totalmente remota a través de una red electrónica $(2015$, p. 271). Su propuesta se basa, principalmente, en que incorporar dentro de la categoría de servicios a los suministros online es forzar el concepto de servicios para incluir bienes intangibles cuya cesión, en realidad, no califica como un servicio (Lamensch, 2015, p. 270). En su opinión, la prestación de servicios implica una actividad (de hacer) del prestador del servicio y no la transferencia de propiedad de un bien (libros electrónicos, música o vídeos).

\section{Sobre el aspecto territorial del impuesto}

Modelos de negocio como la publicidad en línea desafían la estructura tradicional del IVA debido a la relación tripartita entre los clientes (de la publicidad), usuarios (de la plataforma) y el titular de la plataforma digital. Por ejemplo, en el caso de Facebook, la publicidad online puede ser contratada por cualquier empresa y esta puede proyectarse en la pantalla de cualquier persona ubicada en cualquier lugar del mundo. Así, Nike, empresa ubicada en los Estados Unidos, contrata los servicios publicitarios de Facebook, también residente en los Estados Unidos, para publicitar sus productos en la UE.

En este caso, la aplicación de la regla general sobre servicios B2B implicará que el servicio se encuentre sujeto al IVA en los Estados Unidos, país en que Nike tiene su sede de actividad económica (en el escenario en que no exista ningún establecimiento fijo de negocios en la UE). Efectivamente, este servicio no estará gravado en la UE, aun cuando la publicidad se muestre en las pantallas de personas y consumidores finales establecidos en la UE. Para evitar esta distorsión podría aplicarse la regla excepcional de uso y explotación prevista en la Sexta Directiva, pudiendo llegarse a la conclusión de que el uso del servicio se da en el territorio de la UE (donde la publicidad se proyecta), y consecuentemente, este sí se encontraría gravado con IVA en dicha jurisdicción.

Sin embargo, la sujeción a dicha regla no es obligatoria y su aplicación es de libre elección para los países miembros de la Unión Europea, por lo que, eventualmente, parte de los servicios de publicidad de plataformas como Facebook, a pesar de consumirse en la UE, no estarán sujetos a impo-

8 Los servicios prestados vía electrónica, según lo dispuesto en la Directiva 2006/112/CE, deben incluir servicios que se presten a través de internet o de una red electrónica, cuando el proveedor y el destinatario del servicio, debido a la naturaleza digital del servicio, puedan estar situados en diferentes lugares y que sean imposibles de proveer en ausencia de tecnologías de la información [traducción libre]. 
sición en dicha jurisdicción. Esta es una situación bastante particular, ya que ni el prestador del servicio, ni el cliente están ubicados en la UE, por lo que también cabría preguntarse quién de los dos sujetos tendría que asumir el pago del impuesto, de ser el caso que se grave en la UE.

\section{Sobre los mecanismos de recaudación}

La pregunta relacionada con cuál es el mejor mecanismo para asegurar el pago del IVA respecto de transacciones digitales, en las que los actores se encuentran en diversas partes del mundo y su cuantía es inmaterial, no solo ha sido planteada en países que recién incorporan en su legislación el supuesto de servicios digitales, sino que también es discutida en jurisdicciones como la Unión Europea.

Hellerstein resalta que esta problemática surge normalmente cuando el proveedor no se encuentra establecido en la jurisdicción en donde ocurre el consumo. Las interrogantes que -desde su punto de vista- deben responderse en el marco de la economía digital son, por ejemplo, si existen tecnologías disponibles que permitan bloquear de las redes a proveedores que no cumplan sus obligaciones tributarias; o, si no fuera así, si existe la posibilidad de que los proveedores respeten sus obligaciones para evitar exponerse a contingencias tributarias. En todo caso, se plantea si, de forma alternativa, terceros como entidades financieras o agentes de percepción podrían ser responsables de la retención del IVA o, incluso, si los propios consumidores de los servicios debieran efectuar el pago del IVA a la administración tributaria, ello siempre que se pueda emplear la tecnología de la información para asegurar la recaudación (Hellerstein, 2014, pp. 346-351).

Como hemos mencionado, la UE ha optado por confiar en los proveedores de los servicios, situación que parece no ser efectiva. De hecho, a mediados del 2016, 12,899 entidades establecidas en la UE se encontraban registradas como sujetos pasivos que brindan SPE, mientras que solo 1,079 sujetos establecidos fuera de la UE se registraron en el régimen MOSS (Lamensch \& Ceci, 2018). Ahora bien, la Comisión Europea estima que 83,000 empresas establecidas en la UE prestan SPE; sin embargo, no se cuenta con ninguna estimación respecto de las entidades no establecidas en la UE que realmente operan en dicha jurisdicción. En opinión de Lamensch y Ceci, la razón principal de los bajos niveles de recaudación fiscal es la ausencia de medios para verificar el cumplimiento tributario de entidades que operan en la economía digital (2018).

Siguiendo a Lamensch y Ceci, el régimen actual de recaudación de este tipo de servicios no es soste- nible en el tiempo, pues descansa en la buena fe de los sujetos pasivos del impuesto. En ese sentido, los autores recomiendan revisar modelos de recolección alternativos, tales como la retención del IVA por parte de terceros -las entidades financieras que participan al momento del pago-, o el sistema de recolección a partir de los clientes (2018).

Cabe anotar que, recientemente, la Comisión Europea ha lanzado una herramienta digital denominada Transaction Network Analysis (en adelante, TNA). Dicha herramienta permitirá a las autoridades fiscales de cada país miembro acceder en línea a información relacionada con transacciones transfronterizas, a fin de detectar potenciales casos de fraude en relación con el cumplimiento del IVA (Comisión Europea, 2019).

\section{EL RÉGIMEN DE IGV EN EL PERÚ}

En nuestro país se gravan con Impuesto General a las Ventas los siguientes supuestos: la venta de bienes muebles en el país, la prestación o utilización de servicios en el país, la importación de bienes, los contratos de construcción y la primera venta de inmuebles por el constructor.

Como hemos indicado previamente, nuestra Ley del IGV no contiene regulación expresa alguna que se hubiera formulado para gravar los negocios digitales. Sin embargo, es importante explorar la legislación vigente para evaluar, por un lado, si algunas transacciones digitales podrían encontrarse bajo el ámbito de aplicación del IGV y, por otro, los cambios que podrían introducirse en nuestra normativa a fin de sujetar a gravamen al valor generado por los modelos de negocios que han emergido en la era digital, especialmente en relación con transacciones transfronterizas con consumidores (B2C).

\section{A. Alcances generales}

1. Venta de bienes muebles en el país

De acuerdo con la Ley del IGV y su Reglamento, la venta de bienes muebles se configura cuando se transfiere la propiedad sobre bienes considerados muebles. Es decir, la entrega de bienes que no implica la transmisión de los atributos que confiere la propiedad no constituye venta para efectos del citado impuesto (Córdova Arce, 2004, pp. 133-135).

Por otro lado, de acuerdo con el artículo 3 inciso b de la Ley del IGV, son bienes muebles aquellos

[c]orporales que pueden llevarse de un lugar a otro, los derechos referentes a los mismos, los signos distintivos, invenciones, derechos de autor, derechos de llave y similares, las naves, 
aeronaves, así como los documentos y títulos cuya transferencia implique la de cualquiera de los mencionados bienes (Decreto Supremo 055-99-EF, 1999).

Notamos que dicha norma no menciona el término bienes intangibles o incorporales, sino que incluye como bienes muebles a un listado de bienes que, por naturaleza, son intangibles, tales como los signos distintivos, invenciones, derechos de autor, derechos de llave y similares. Ello ha originado que surjan discusiones en cuanto al alcance del concepto de bienes muebles.

En efecto, Córdova Arce considera que la norma antes mencionada podría interpretarse de tres formas: (i) que todos los intangibles califican como bienes muebles; (ii) que solo los intangibles enumerados en dicha norma califican como bienes muebles, incluyendo los semejantes a los derechos de llave; y, como postura intermedia, (iii) podrían calificar como bienes muebles los intangibles enumerados en la citada disposición y sus similares, es decir, no solo los bienes similares a los derechos de llave, sino también a los signos distintivos, invenciones, derechos de autor (2004, pp. 136-138).

Por su parte, Villanueva Gutiérrez considera que "la inclusión prevista en la norma vigente no abarca a todo derecho incorporal o inmaterial, sino solamente a los expresamente considerados en la norma y sus similares" (2014, p. 10). Sin embargo, menciona que, desde otra perspectiva, esta interpretación podría resultar incongruente con la exposición de motivos de la norma que incorporó a dichos bienes como bienes muebles, ya que el objetivo del legislador habría sido lograr la neutralidad del IGV de modo que este aplique tanto a las transacciones de venta de intangibles, como cesiones temporales de los mismos -bajo el rubro de prestación de servicios (2014, pp. 113-114). En efecto, una interpretación restrictiva de la definición de los intangibles considerados bienes muebles puede implicar que ciertas transferencias de propiedad de intangibles no se encuentren gravadas con el impuesto, mientras que la cesión temporal de dichos bienes siempre estaría gravada, independientemente del tipo de intangible de que se trate.

De acuerdo con esta última perspectiva, la administración tributaria ha tomado postura, aclarando que el término similares hace referencia a todos los intangibles, o bienes inmateriales. Por el contrario, el Tribunal Fiscal, en la Resolución 2424-52002, no ha adoptado ninguna de las interpretaciones antes mencionadas, sino que concluye que el término similares se refiere únicamente a aquellos bienes intangibles que mantienen la naturaleza de bien mueble de acuerdo con el Código Civil. A partir de estos comentarios, resulta claro que la discusión sobre el alcance de la definición de bienes muebles en relación con los intangibles no ha sido zanjada y es controversial.

En cuanto al aspecto espacial, a efectos de que la venta se realice en el país, los bienes deben encontrarse ubicados físicamente en el territorio nacional. Sin embargo, tratándose de intangibles, la Ley del IGV presume que estos se encuentran ubicados en el país cuando el proveedor y el adquirente se encuentran domiciliados en el país ${ }^{9}$. Es decir, la adquisición de intangibles a sujetos no domiciliados no se encontrará sujeta a imposición bajo este supuesto.

\section{Prestación y utilización de servicios en el país}

El inciso c del artículo 3 de la Ley del IGV establece que se entiende por servicios toda prestación que una persona realiza para otra y por la cual percibe una retribución que constituye renta de tercera categoría para efectos del Impuesto a la Renta, es decir, rentas empresariales. En opinión de Villanueva Gutiérrez, por prestación debe entenderse "cualquier conducta que constituya el contenido de una relación jurídica obligatoria, excluida la prestación destinada a transferir la propiedad de los bienes" (2014, p. 130). Por su parte, en la Resolución 2154-2009, el Tribunal Fiscal ha concluido que el término prestación comprende las obligaciones de dar -salvo aquellas que conlleven la transmisión de propiedad del bien, en cuyo caso estaríamos frente a una venta-, las de hacer y las de no hacer.

En cuanto al aspecto espacial, de acuerdo con el inciso c del artículo 3 de la Ley del IGV, el servicio es prestado en el país cuando el sujeto que lo presta se encuentra domiciliado en este para efectos del Impuesto a la Renta, sea cual fuere el lugar de celebración del contrato o del pago de la retribución. Por otro lado, el servicio es utilizado en el país cuando, si bien es prestado por un sujeto no domiciliado, es consumido o empleado en el territorio nacional. En este último caso, la persona natural o jurídica que realice actividad empresarial o que sea habitual y que utilice los servicios prestados por no domiciliados en el país será contribuyente del impuesto.

Cabe indicar que el objetivo de la Ley del IGV no es gravar operaciones entre consumidores finales, por ello es que establece que el sujeto pasivo en

Nótese que el término domicilio se definirá conforme a lo establecido en la Ley del Impuesto a la Renta. 
la prestación y en la utilización de servicios debe realizar actividad empresarial o ser habitual (Luque Bustamante, 2000, p. 95). De acuerdo con el artículo 4 numeral 1 del Reglamento de la Ley del IGV, para calificar la habitualidad se considerará "la naturaleza, características, monto, frecuencia, volumen y/o periodicidad de las operaciones a fin de determinar el objeto por el cual el sujeto las realizo" (Decreto Supremo 29-94-EF, 1994). Agrega dicha norma que "tratándose de servicios siempre se considerarán habituales aquellos servicios onerosos que sean similares con los de carácter comercial" (Decreto Supremo 29-94-EF, 1994).

En ese sentido, el Tribunal Fiscal ha indicado a través de la Resolución 6418-1-2014 que ninguna norma regula la cantidad de veces que una persona deba utilizar un servicio para que califique como habitual. Por dicha razón, debe analizarse la frecuencia y el monto y, solo cuando estos criterios evidencien que dichas operaciones tienen un objeto mercantil, el individuo será sujeto pasivo del impuesto.

En resumen, los servicios prestados por no domiciliados se encuentran gravados en el país, cuando se presenten las siguientes condiciones: (i) califiquen como servicios, (ii) sean onerosos, (iii) se consuman en el territorio nacional y, (ii) el usuario del servicio califique como sujeto pasivo del IGV, esto es, porque realiza actividades empresariales o, si no las realiza, en la medida en que califique como habitual. Si alguna de estas condiciones no se presenta, el servicio prestado por un no domiciliado a un sujeto domiciliado en el Perú se encontraría fuera del ámbito de aplicación del impuesto.

\section{Importación de bienes}

Hasta la modificación introducida por la Ley 30264 , Ley que establece medidas para promover el crecimiento económico, la cual introdujo en la Ley del IGV el concepto de importación de intangibles, se consideraba que la importación de bienes únicamente se refería a bienes corpóreos y no a intangibles $^{10}$. En efecto, el Tribunal Fiscal, en la Resolución 04091-3-2003, acudió a la definición de importación prevista en la Ley General de Aduanas para dar contenido al concepto de importación estipulado en la Ley del IGV.

En virtud de la citada norma, la importación consiste en el procedimiento de ingreso legal de mercancías al territorio nacional para su consumo, en consecuencia, el citado tribunal concluyó que el aporte de una marca por parte de un no domiciliado, a favor de una empresa domiciliada, no constituía una importación, pues no era posible verificar el ingreso de la mercancía al territorio peruano. Dicha conclusión se amparaba también en que el nacimiento de la obligación tributaria, según el inciso g) del artículo 4 de la Ley el IGV, ocurría en la fecha en que se solicitaba el despacho a consumo. Esta situación de hecho es de imposible cumplimiento cuando se adquieren bienes intangibles del exterior.

Ahora bien, mediante la Ley 30264 se incorporó el inciso g) del artículo 3 de la Ley del IGV que define la importación de bienes intangibles en los siguientes términos: "La adquisición a título oneroso de bienes intangibles a un sujeto domiciliado en el exterior por parte de un sujeto domiciliado en el país, siempre que estén destinados a su empleo o consumo en el país" (Ley 30264, 2014). El término adquisición no se encuentra definido en la Ley del IGV. Al respecto, el Diccionario de la Lengua Española establece que el término adquirir significa: "ganar, conseguir con el propio trabajo o industria, comprar (obtener un precio)" (2014). Al respecto, el Código Civil establece en su artículo 1529 que por "la compraventa el vendedor se obliga a transferir la propiedad de un bien al comprador y éste a pagar su precio en dinero" (Decreto Legislativo 295, 1984).

A partir de dicha lectura, podría inferirse que la importación de un intangible se configura cuando ocurre la transferencia de propiedad (o de titularidad) sobre un bien de dicha naturaleza. Por el contrario, si es que no estuviéramos frente a una transacción en virtud de la cual se transfiere la propiedad sobre un bien, podría evaluarse la aplicación de la regla de utilización de servicios. En efecto, es necesario establecer en qué casos nos encontramos frente a la importación de intangibles y en qué situaciones

Debemos indicar que esta norma fue incorporada como parte de un paquete de medidas para evitar la doble imposición cuando la retribución por la utilización de servicios a su vez formaba parte del valor en aduanas de un bien importado al país. En ese contexto, la Ley 30264 deroga el inciso e) del artículo 2 de la norma reglamentaria del IGV que establecía que "tratándose de bienes intangibles provenientes del exterior, el Impuesto se aplicará de acuerdo a las reglas de utilización de servicios en el país, en el caso en que Sunat (Aduanas) hubiera efectuado la liquidación y el cobro del Impuesto, este se considerará como anticipo del impuesto que en definitiva corresponde" (Decreto Supremo 29-94-EF, 1994). En virtud de dicha norma, la Sunat (en el Informe 305-2005-SUNAT/2B0000) entendía que la elaboración un software a pedido por un no domiciliado constituía un servicio utilizado en el país y, a su vez, la importación del software calificaba como importación de un bien intangible sujeto al IGV. Esta interpretación también fue plasmada en la Exposición de Motivos de la Ley 30264 como base para la modificación introducida por la citada ley. 
estaríamos frente a su cesión temporal, supuesto gravado bajo el rubro servicios. En el siguiente punto de este artículo exploraremos las diferentes posiciones que existen en relación con la calificación de una transacción como venta de intangibles o como servicios.

Cabe anotar que, en el supuesto de importación, se hace referencia al término intangibles, a diferencia del régimen de venta de bienes muebles en el país, en el que subsiste la discusión sobre si este alcanza a todos los intangibles o solo a los similares a los bienes detallados en la norma. Siendo así, cualquier adquisición de intangibles del exterior estaría sujeta a imposición en el país, mientras que la venta en el país sujeta a IGV se limita a aquellos bienes considerados muebles.

Por otro lado, en cuanto al sujeto pasivo, el artículo 9 de la Ley del IGV diferencia entre sujetos que se dedican a actividades empresariales y aquellos que no. En el primer caso, son sujetos pasivos quienes realizan las actividades gravadas, incluyendo la importación de bienes. Por su parte, las personas (naturales o jurídicas) que no realizan actividad empresarial serán el sujeto pasivo siempre que importen bienes o sean habituales en la realización de las otras actividades. En efecto, el requisito de habitualidad no ha sido contemplado para la importación de bienes y califica como importador cualquier sujeto que importe un bien al Perú, incluidos los consumidores finales de los bienes.

La Ley 30264 introdujo una precisión en cuanto a la calidad de sujeto pasivo de las personas que realizan actividad empresarial. Es así que, en el caso de importación de bienes, el inciso f del artículo 9.2 de la Ley de IGV precisó que "tratándose de bienes intangibles se considerará que importa el bien el adquirente del mismo" (Decreto Supremo 055-99$E F, 1999)$. Dicha precisión no fue incorporada en el caso de personas que no realizan actividad empresarial. En efecto, el artículo 9.2 de dicha Ley se ha mantenido intacto y únicamente dispone que son sujetos pasivos quienes importan bienes afectos.

Nos preguntamos entonces si esta omisión en la Ley 30264 implica que aquellos individuos o consumidores finales que adquieran bienes intangibles del exterior no calificarían como sujetos pasivos, pero sí aquellos que realizan actividades empresariales. Sobre ello, de una lectura sistemática de la Ley de IGV, y considerando la definición de importación de intangibles, que consiste en la adquisición de bienes intangibles para su consumo en el Perú, se podría inferir que "importa el bien intangible" quien lo adquiere (Decreto Supremo 055-99-EF, 1999). Sin embargo, la omisión de la Ley 30264 podría dejar la puerta abierta para otras interpretaciones.
Por su parte, a diferencia de la importación de bienes tangibles, en los que la base imponible está dada por el Valor en Aduanas del bien más los derechos que graven la importación, la base imponible en la importación de intangibles estará dada por el valor de venta.

Finalmente, es importante destacar que, con respecto a la importación de bienes tangibles, la Ley 29774, Ley que complementa la normativa sobre la importación de los envíos de entrega rápida o equivalentes, aprobó la inafectación del IGV respecto de envíos de entrega rápida, cuando las mercancías importadas no superen el valor de 200 dólares americanos. Ello implica que, si un sujeto adquiere bienes de menor valor vía alguna plataforma digital, estos no estarán gravados con el IGV al momento de su importación al país.

\section{Adquisición de contenido digital: venta o servicio}

A partir de la lectura de la Ley de Derechos de Autor, Luque Bustamante (2000) concluyo que la venta de ejemplares de la obra implica el ejercicio del derecho moral del autor (de poner la obra en conocimiento del público) y, a su vez, de sus derechos patrimoniales, como el derecho a la distribución. En su opinión, quien distribuye o comercializa una obra o el ejemplar de la misma, realiza "una prestación de hacer a favor del receptor de la obra, al autorizarle o permitirle el legítimo goce o disfrute personal de la creación artística, literaria, musical, [etcétera]" (pp. 103-105). En este sentido, este mismo autor concluye que la adquisición del soporte físico en ningún modo implica la transmisión de derechos de autor sobre la obra y, en el mismo sentido, la descarga (download) de la obra digitalizada tampoco implica la transferencia en propiedad de bien alguno, pues no transfiere al usuario derechos patrimoniales sobre la obra digitalizada (pp. 103-105).

En el mismo sentido, Córdova Arce, refiriéndose a la venta de bienes muebles en el país, considera que la transferencia de propiedad o de la titularidad sobre los intangibles -considerados mueblesoperará cuando estos salgan de la esfera patrimonial del transferente, de modo que "el adquirente obtenga los derechos de use, disfrute y disposición" (2004, p. 135). Agrega que "en el caso de los derechos de autor, tal transferencia solo puede referirse a los derechos de carácter patrimonial, mas no así a los de orden moral que son inalienables" (p. 135).

Por otro, el Tribunal Fiscal, mediante la Resolución 00045-8-2018, discutía si la adquisición de copias de software -en este caso, antivirus- para su poste- 
rior comercialización en el país, califica como venta de bienes muebles y no como prestación de servicios. Al respecto, el Tribunal Fiscal considera que la venta de copias del software no implica la cesión de la titularidad sobre el derecho de autor, ni tampoco es un contrato de licencia de uso de software, sino que, teniendo en cuenta el giro del negocio de la apelante, así como la cantidad de bienes adquiridos, la operación califica como una compra venta de bienes $-y$ no una prestación de servicios- que forma parte de una cadena de comercialización de este tipo de mercadería, donde los proveedores del software califican como distribuidores.

Es indudable que este tema admite diversas interpretaciones, como las adoptadas por la doctrina nacional y el Tribunal Fiscal. En todo caso, si se aplicara la lectura del Tribunal Fiscal, la adquisición de software u otros intangibles, como música, vídeos, entre otros (que califican como copias del bien) constituiría una venta y no un servicio. Cabe señalar que esta discusión tiene impacto en el alcance de la importación de intangibles, pues este supuesto solo ocurrirá cuando se ha configurado su adquisición, es decir, cuando se verifica la venta o transferencia de propiedad sobre dichos bienes.

\section{B. Comentarios sobre el régimen vigente en la Ley del Impuesto General a las Ventas en la era de la digitalización}

1. Respecto a la venta en el país de bienes muebles

Los productos o servicios digitales en su mayoría provienen de empresas residentes fuera del país, principalmente en Estados Unidos y Europa, en consecuencia, esta hipótesis de incidencia, por sí sola, no tendría mayor impacto en cuanto al tratamiento de las transacciones digitales. Sin perjuicio de ello, la definición actual de bienes muebles, y que es restringida en el rubro de intangibles, implica que no todas las transacciones de venta sobre bienes de naturaleza incorpórea se encuentran gravados con el IGV. Por otro lado, definir si la transferencia o adquisición de contenido digital (de obras, software, u otros) -que no implica la transferencia de titularidad sobre los derechos patrimoniales- califica o no como venta es relevante para determinar el alcance de la importación de intangibles provenientes del exterior.

2. Sobre la utilización de servicios de no domiciliados

Los servicios prestados por no domiciliados únicamente se encuentran gravados cuando son utilizados en el Perú por sujetos que realizan actividad empresarial o son habituales (es decir, transaccio- nes B2B). En el contexto de la economía digital, ello implicaría que los servicios tales como servicios de intermediación, publicidad online, y cesión temporal de bienes intangibles (de contenido digital) se encontraría sujeta a imposición, en nuestro país, siempre que se cumplan las condiciones antes mencionadas.

Consecuentemente, las transacciones con consumidores finales no estarían sujetas al impuesto, por lo que la esencia o el core de la economía digital quedaría fuera del ámbito de aplicación del impuesto. En efecto, los servicios de intermediación como los de Airbnb, Uber, e-games, entre otros, estarían fuera del alcance del IGV, aun cuando estos se consuman en el país.

Sin perjuicio de ello, nos preguntamos si podría interpretarse que la utilización frecuente de plataformas digitales por parte de los individuos podría calificar como habitual en los términos de la Ley del IGV. En este sentido, la posición adoptada por el Tribunal Fiscal es acertada, en tanto los indicadores de frecuencia, volumen, periodicidad deben evaluarse para verificar si los usuarios se encuentran realizando actividades comerciales o mercantiles, en otras palabras, si en realidad los servicios son utilizados en el marco de una actividad económica y escapan de su esfera personal. Al respecto, los usuarios que interactúan en el mundo digital normalmente lo hacen como parte de sus intereses personales y no con fines económicos, por lo que, en principio, no deberían calificar como sujetos pasivos del impuesto.

\section{Importación de bienes intangibles}

Un aspecto importante de la economía digital es la adquisición online de acceso a contenido digital o soluciones digitales (intangibles). Al respecto, en algunos casos el acceso al contenido digital se da únicamente a través de las plataformas digitales y el usuario no adquiere una copia de la obra -fuera de la plataforma-, como es el caso de Netflix. En otros, los usuarios sí adquieren una copia de la obra, software, música, entre otros; por ejemplo, tenemos a los productos ofrecidos por Apple o Microsoft, copia que es descargada a los dispositivos personales de los usuarios.

En el primer escenario, estaríamos frente a la prestación de un servicio que podría estar gravado bajo el rubro de utilización de servicios en los términos antes mencionados (Luque Bustamante, 2000, pp. 102). Sin embargo, en el segundo caso, considerando la jurisprudencia del Tribunal Fiscal, cuando el usuario adquiere una copia o hace descarga un producto digital a algunos de sus dispositivos (celular, computador y otros) para consumirlo en 
el Perú y el proveedor es no domiciliado, entonces podríamos encontrarnos frente a la importación de un intangible.

Si bien, tratándose de importación, incluso los consumidores finales son sujetos pasivos del impuesto, no existe ningún incentivo para que un consumidor declare y pague directamente el impuesto al fisco peruano, cuando este no tiene medios para detectar dichas transacciones. Así, si bien sobre la base del régimen de importación de intangibles sería posible sujetar a gravamen algunas transacciones digitales, dicho régimen no es efectivo ni práctico en relación a operaciones $\mathrm{B} 2 \mathrm{C}$, pues no contempla mecanismos eficientes de recaudación del fisco. Es, pues, evidente que el régimen actual de importación de intangibles no pretende dar respuesta a la problemática de la era digital, sino que fue concebido para solucionar un problema específico al momento de la importación de bienes.

\section{Inafectación a bienes de menor valor}

La inafectación a la importación de bienes tangibles cuyo valor es menor a 200 dólares americanos implicaría que parte de las transacciones comerciales B2C no se sujeten a imposición en el país. Este tipo de inafectación constituye un foco de preocupación a nivel de la Unión Europea y de la OCDE, pues la venta de bienes de poco valor mediante plataformas digitales genera gran parte de los ingresos de sitios web como Amazon, eBay y Alibaba.

En conclusión, si bien el régimen vigente del IGV contiene normas que regulan operaciones internacionales, estas claramente no están pensadas para gravar los modelos de negocio de la economía digital.

\section{Algunas ideas y comentarios para moder- nizar el régimen de Impuesto General a las Ventas en el Perú en el marco de la econo- mía digital}

Como hemos observado, es necesario modernizar las normas del IGV de modo que estas se encuentren preparadas para sujetar a gravamen el valor añadido en la era digital. Surge la interrogante acerca de cuál debería ser el mejor camino a seguir para que nuestra legislación cumpla con los principios de política fiscal identificados por la OCDE y, a su vez, asegure una recaudación eficiente en relación con las transacciones digitales. Ahora bien, el objetivo de este trabajo no es brindar propuestas concretas de modificaciones en la legislación, pero si colaborar con una lluvia de ideas que genere hilos de discusión en materia de IGV y la economía digital.
Cabe mencionar que, desde nuestro punto de vista, las normas que regulan los supuestos básicos gravados con el IGV -esto es, venta, servicios e importación- es que, si bien dichas normas pueden resultar sencillas de aplicar en transacciones ordinarias como la compraventa o importación de un bien tangible, o la prestación de servicios en el país; cuando empezamos a ahondar en las normas en temas más sofisticados, como el tratamiento de los intangibles, estas adquieren un alto grado de complejidad y de incertidumbre. En ese sentido, nos preguntamos si sería necesario modificar las normas desde su base, en lugar de ir colocando parches en la legislación que deriven en un sistema aún más complejo y menos eficiente.

En este sentido, en primer lugar, resultaría conveniente evaluar la posibilidad de incorporar un sistema similar al previsto en la Sexta Directiva de la UE. Ello implica, por un lado, definir la venta de bienes muebles, como la transferencia de propiedad de bienes corpóreos o tangibles y, por otro, definir servicios de forma residual, como todas las operaciones que no constituyen venta de bienes. De este modo, el alcance de servicios sujetos a IGV incluiría cualquier transacción en materia de intangibles (desde la adquisición, cesión, licencia de uso, entre otras). Una modificación a este nivel brindaría mayor certeza, simplicidad y neutralidad al sistema del IGV. En efecto, las discusiones sobre la definición de bienes muebles, o en qué circunstancias ocurre la transferencia de propiedad de un intangible se resolverían. Asimismo, el nacimiento de la obligación tributaria, entre otros aspectos de la hipótesis de incidencia, sería idéntico en todas las transacciones relacionadas con intangibles $y$ con servicios digitales.

No obstante, una modificación de esta naturaleza implicaría revisar de forma íntegra y comprehensiva la legislación del IGV, debido a que, en virtud de este sistema, cualquier operación quedaría gravada, por lo que sería muy importante reevaluar temas como el alcance de las inafectaciones tributarias y aquellas operaciones que tendrían que mantenerse al margen del ámbito de aplicación del IGV.

Adicionalmente, sea que se evalúe o no esta modificación en la definición de venta y servicios, si lo que se quiere es gravar los modelos de negocio que operan en la economía digital, resultaría necesario ampliar el objeto del IGV para que pueda alcanzar a las transacciones internacionales realizadas con consumidores (B2C) establecidos en el país. En este sentido, podría incorporarse como supuesto gravado con el IGV a los servicios prestados por medios electrónicos a favor de sujetos que no realizan actividad empresarial y que se consuman o utilicen en el país. 
Los servicios prestados electrónicamente podrían definirse en los términos sugeridos por Merkx (2018), como servicios prestados a través de internet o de una red electrónica, en los cuales el proveedor -no domiciliado- y el destinatario de los servicios, debido a la naturaleza digital de estos, pueden estar ubicados en diferentes lugares y que no tienen viabilidad al margen de la tecnología de la información. Esta propuesta resulta interesante pues, permite abarcar la amplia variedad de servicios digitales que se prestan a través de internet $y$, como hemos mencionado antes, elimina el requisito de automatización y mínima intervención humana previsto en la Sexta Directiva, que puede generar distorsiones y es inflexible a los diferentes modelos de negocio de la era digital.

Ahora bien, al igual que se regula en la UE, sería importante que dicha definición venga acompañada de ejemplos no exhaustivos, en cuanto a qué se considera servicios prestados electrónicamente. Incluso, podría incluirse el suministro de productos digitalizados en general, incluidos, entre otros, los programas informáticos, sus modificaciones y sus actualizaciones, así como el acceso y/o la descarga de software, imágenes, texto, información, vídeo, música, juegos, películas, libros electrónicos, diseños, imágenes, y otras publicaciones electrónicas.

Además de ello, podría hacerse referencia a la publicidad en línea, la difusión de música y películas, las apuestas online o el acceso a cualquier contenido digital, incluyendo el contenido al que se accede a través de tecnología de emisión en directo (streaming). También podría contemplarse incluir la concesión del derecho a comercializar un bien o servicio en un sitio de internet que funcione como un mercado en línea, como los servicios de subastas en línea.

En cuanto al aspecto espacial, se sugeriría presumir que el servicio es consumido o utilizado en el país cuando es prestado a un sujeto -quien no realiza actividad empresarial- y que se encuentra establecido, domiciliado o es residente habitual del Perú. Adicionalmente a ello, sería importante regular en qué situaciones se puede presumir que el sujeto está establecido en el país.

Como hemos señalado, respecto de transacciones con países que no son miembros de la Comunidad Europea, la Sexta Directiva considera que dicha presunción opera cuando se presenten dos elementos de prueba no contradictorios, que pueden ser la dirección de facturación del cliente, la dirección de protocolo internet del dispositivo utilizado por el cliente o cualquier sistema de geolocalización, los datos bancarios, entre otros. Cabría evaluar, sin embargo, si en lugar de dos ítems, podría requerirse únicamente un elemento de prueba a fin de facilitar el cumplimiento tributario, tal como lo hace la UE respecto de las transacciones intracomunitarias.

Adicionalmente, es importante que se establezcan presunciones que permitan confirmar que el sujeto receptor de los servicios se encuentra establecido en el Perú, a fin de darle mayor certeza a este régimen y evitar interpretaciones sobre la ubicación del sujeto y sobre dónde se realiza el consumo o utilización del servicio. Sin perjuicio de ello, cabría evaluar la posibilidad de dejar la puerta abierta para que dichas presunciones puedan ser rebatidas con otros medios de prueba.

En cuanto a los mecanismos de recaudación, la Sexta Directiva de la UE ha establecido el régimen del MOSS, por el cual los proveedores del exterior de este tipo de servicios deben registrarse en algún país miembro de la UE y tributar directamente el IVA. Por otro lado, la reciente legislación argentina ha planteado un mecanismo por el cual las entidades del sistema financiero deben retener el IGV en las transacciones digitales (Cepal, 2019). Por su parte, la legislación colombiana, también reciente, ha planteado un mecanismo mixto de recaudación, bajo el cual los proveedores tienen la obligación de inscribirse y hacer el pago directo del IVA o pueden optar por que se efectúe la retención por parte de las entidades del sistema financiero (Cepal, 2019).

En el Perú, probablemente el camino más efectivo sería optar por un mecanismo similar al seguido por Colombia o Argentina, y no por el sistema europeo. Las razones son varias. Una de ellas es que el nivel de cumplimiento de la normativa comunitaria es bajo. Incluso tomando en cuenta la magnitud de la economía europea y las diversas herramientas con que dicha jurisdicción cuenta para el intercambio de información, los proveedores, especialmente aquellos ubicados fuera de la UE no encuentran los incentivos necesarios para cumplir con las obligaciones tributarias impuestas por esta. Tanto es así que, como hemos mencionado, están en discusión mecanismos alternativos de recaudación del IVA.

Ahora bien, situándonos en el contexto peruano, nuestra economía digital es de mucha menor envergadura puesto que no contamos con el presupuesto ni herramientas de intercambio de información con que ya cuenta la UE -como el TNApara fiscalizar y detectar omisiones tributarias. En consecuencia, los proveedores establecidos fuera del país no tienen incentivos económicos para cumplir sus obligaciones fiscales, ni nuestra administración tributaria cuenta con los medios para 
hacer cumplir las reglas peruanas. En este escenario, confiar en que la recaudación llegará a las arcas peruanas por la buena fe de los proveedores no parece un camino efectivo, siendo así, una alternativa razonable y que ya viene siendo aplicada por los países de la región, la retención por parte de las entidades que administran los pagos en este tipo de transacciones.

Asimismo, algunas consideraciones adicionales son las siguientes:

- La incorporación de este supuesto implicaría la necesidad de derogar las normas relacionadas a la importación de intangibles, pues la adquisición de intangibles por parte de sujetos no domiciliados se encontraría sujeta al supuesto de servicios prestados electrónicamente. Sin embargo, en caso se opte por mantener las normas de importación de intangibles -esto es, la distinción entre venta de intangibles y servicios asociados a dichos bienes- sería importante que dicho régimen también prevea el mismo mecanismo de recaudación a aquel que se establezca para los servicios prestados por vía electrónica, específicamente en el caso de operaciones B2C.

- Sería conveniente que el supuesto de servicios prestados de forma electrónica constituya una hipótesis de incidencia independiente de los servicios utilizados económicamente en el país y de la importación de bienes, a fin de que sus particularidades puedan ser reguladas adecuadamente. Asimismo, en relación con los servicios utilizados en el país, podría precisarse que, únicamente los sujetos que realizan actividad empresarial son sujetos pasivos y no los que son habituales. Ello, con el objeto de evitar discusiones innecesarias en cuanto al alcance de la habitualidad en relación con los usuarios de las plataformas digitales.

- Considerando que los servicios gratuitos no se encuentran sujetos al IGV en el Perú, al igual que en la UE, cabría la pregunta acerca de si los servicios brindados por algunas plataformas digitales a cambio del derecho a explotar la data de los usuarios de dicho servicio podrían calificar como un servicio oneroso -donde el derecho a la data es el precio del servicio- y no como un servicio gratuito. Si fuera un servicio oneroso, este calificaría como servicio prestado por vía electrónica y, en consecuencia, estaría sujeto al IGV.

- Cabría revisar si alguna de las exoneraciones sobre bienes o servicios debería extender- se a su formato digital a fin de garantizar la neutralidad del impuesto. Por ejemplo, en el caso de los libros electrónicos, el servicio de taxi (plataformas como Uber), la educación a distancia (e-learning), a fin de mantener la neutralidad entre bienes o servicios que tienen el mismo objeto, donde uno es tangible y el otro digital. Ahora bien, si es que se optara por extender la exoneración a ciertos servicios digitales, la recaudación por medio de la retención de las entidades financieras sería más compleja, pues tendrían que establecerse mecanismos para que dichas entidades puedan diferenciar entre servicios gravados y no gravados; circunstancia que vemos remota, si es que no se cuenta con la participación activa del proveedor del servicio quién si contaría con la información suficiente para definir si su servicio se encuentra sujeto o no al IGV.

- $\quad$ Finalmente, en cuanto al comercio electrónico propiamente dicho, es decir, la adquisición de bienes (tangibles), por medio de una plataforma digital, convendría evaluar en términos de costo-beneficio si se mantiene la inafectación a los bienes de menor valor que son importados al Perú por medios de entrega rápida, o en todo caso si se disminuye el valor inafecto. Este punto requiere, en opinión de la OCDE (2015), una acción inmediata para que las ganancias de las grandes plataformas como Amazon o eBay no escapen a la tributación del IVA.

\section{CONCLUSIONES}

La Sexta Directiva contiene un marco legal sólido para gravar con IVA las transacciones digitales en la Unión Europea. Su experiencia y ejemplo podrían servir de base para regular el tratamiento del IGV a la economía digital en el Perú. Más aún, cuando la UE fue la primera jurisdicción en introducir reglas para sujetar a gravamen las transacciones digitales en operaciones $\mathrm{B} 2 \mathrm{C}$.

Las normas peruanas en materia de operaciones digitales están desfasadas en el tiempo: son complejas e inefectivas en términos de recaudación. Por dicha razón, es necesario modernizarlas de modo que se adapten a la economía digital. La introducción del concepto de servicios prestados electrónicamente a consumidores que no realizan actividad empresarial o que no califican como sujeto pasivo del impuesto constituye una opción viable y efectiva.

El mecanismo de recaudación ideal podría ser uno mixto que combine la participación de los provee- 
dores, y la obligación de retener el IGV por parte de las entidades financieras al momento del pago. Es necesario definir algunos conceptos adicionales, como qué se entiende por consumidor, en qué circunstancias el servicio se entenderá consumido en el país, entre otros. Asimismo, sería conveniente dejar de lado el concepto de importación de intangibles y precisar el alcance de la utilización de servicios en el país para evitar la superposición de supuestos gravados con el IGV.

\section{REFERENCIAS}

Adquirir (2014). En Diccionario de la lengua española (23era ed.). Redirigido de: https://dle.rae. es/adquirir.

Bal, A. (2019). The Changing Landscape of the EU VAT: Digital VAT Package and Definitive VAT System. European Taxation, 59(2).

Comisión Económica para América Latina y el Caribe (2019). Programa Fiscal de América Latina y el Caribe 2019. Recuperado de: https://repositorio.cepal.org/bitstream/handle/11362/44516/1/S1900075_es.pdf.

Comisión Europea (2018). Commission Staff Working Document Impact Assessment accompanying the document Proposal for a Council Directive laying down rules relating to the corporate taxation of a significant digital presence and Proposal for a Council Directive on the common system of a digital services tax on revenues resulting from the provision of certain digital services (81 final). Recuperado de: https://ec.europa.eu/transparency/regdoc/ rep/10102/2018/EN/SWD-2018-81-F1-ENMAIN-PART-1.PDF.

(15 de mayo de 2019). VAT Fraud: New tool to help EU countries crack down on criminals and recoup millions. Recuperado de: https:// ec.europa.eu/commission/presscorner/detail/ en/IP_19_2468.

Córdova Arce, A. (2004). El régimen del Impuesto General a las Ventas a los intangibles en el Perú y su implicancia en transacciones internacionales. Ius et Veritas, (29), pp. 132-141.

Kofler G., Mayr G. \& C. Schlager (2018). Taxation of the digital economy: a pragmatic approach to short-term measures. European Taxation, 18(4), pp. 123-129. https://koflerge.files.wordpress.com/2019/01/et_2018_04_int_1.pdf.

Hargitai, C. (2001). Value Added Taxation of Electronic Supply of Services within the European
Community (The Jean Monnet Program working paper 13/01). Recuperado de la página web del Jean Monnet Center for International and Regional Economic Law \& Justice https://jeanmonnetprogram.org/archive/papers/01/013301.html.

Hellerstein, W. (2014). Jurisdiction to Tax in the Digital Economy: Permanent and Other Establishments. Bulletin for International Taxation, 68(6), pp. 346-351.

Ivinson, J. (2004). VAT and Technology. Haywards Heath: Tolley Publishing.

Lamensch, M. (2015). European Value-added Tax in the Digital Era. A Critical Analysis and Proposals For Reform. International Bureau of Fiscal Documentation. Amsterdam: Departamento Internacional de Documentación Fiscal. http:// hdl.handle.net/2078.1/203498.

(2017). European Commission's New Package of Proposals on E-Commerce: A Critical Assessment. International VAT Monitor, 28 (2), pp. 137-146.

Lamensch, M. \& Ceci, E. (2018). VAT fraud: Economic impact, challenges and policy issues (PE 626.076). Recuperado de http:// www.europarl.europa.eu/RegData/etudes/ STUD/2018/626076/IPOL_STU(2018)626076_ EN.pdf.

Luque Bustamante, J. (2000). El Impuesto General a las Ventas y el Comercio Electrónico. VI Jornadas Nacionales de Derecho Tributario. Revista del Instituto Peruano de Derecho Tributario, (38), pp. 69-121. https://www.ipdt.org/ uploads/docs/03_Rev38_JLB.pdf.

Merkx, M. (2018). VAT and E-Services: When Human Intervention Is Minimal. International VAT Monitor, 29 (1).

Organización para la Cooperación y el Desarrollo Económico (1998). Resumen: Tributación fiscal y comercio electrónico. Implementación del marco tributario de la Conferencia de Ottawa. Recuperado de http://www.oecd.org/ctp/administration/2673607.pdf.

(2015). Addressing the Tax Challenges of the Digital Economy Action 1 - 2015 Final Report. París: OECD Publishing. https://dx.doi. org/10.1787/9789264241046-en.

(2017). International VAT/GST Guidelines. París: OECD Publishing. https://doi. org/10.1787/9789264271401-en. 
(2019). The role of digital platforms in the collection of VAT/GST on online sales, as presented for consideration at the fifth meeting of the Global Forum on VA. París: OECD Publishing. https://doi.org/10.1787/e0e2dd2d-en.

Papis-Almansa, M. (2019). VAT and Electronic Commerce: The New Rules as a Means for Simplification, Combating Fraud and Creating a more Level Playing field? ERA Forum, 20 (2), pp. 221-223. https://doi.org/10.1007/s12027019-00575-9.

Pfeiffer, S. (2015). Taxable persons in direct taxation. En Ursprung, M. (Ed.), Global Trends in VAT/GST and Direct Taxes (93, pp. 165-195). Viena: Linde Verlag.

(2016). VAT on "Free" Electronic Services? International Tax Monitor, 27 (3), pp. 160.

Schön, W. (2018). Ten questions about why and how to tax the digitalized economy. Bulletin for International Taxation, 72(4), pp. 278-292.

Schenk, A. y Oldman, O. (2007). Value Added Tax: A Comparative Approach. Cambridge Law Series. Cambridge: Cambridge University Press.

Terra, B. y Kajus J. (2014). A guide to the European VAT Directives, Introduction to European VAT 2008. Amsterdam: IBFD.

Villanueva Gutiérrez, W. (2014). Tratado del IGV regímenes general y especiales. Lima: Pacifico editores.

\section{LEGISLACIÓN, JURISPRUDENCIA Y OTROS DOCU- MENTOS LEGALES}

Decreto Legislativo 295. Código Civil. Diario Oficial El Peruano, 25 de julio de 1984.

Decreto Supremo 055-99-EF. Texto Único Ordenado de la Ley del Impuesto General a las Ventas e Impuesto Selectivo al Consumo. Diario Oficial El Peruano, 15 de abril de 1999.

Decreto Supremo 29-94-EF. Reglamento de la Ley del Impuesto General a las Ventas e Impuesto Selectivo al Consumo. Diario Oficial El Peruano, 29 de marzo de 1994

Directiva 2006/112/CE de la Comunidad Europea. Directiva 2006/112/CE del Consejo, de 28 de noviembre de 2006, relativa al sistema común del impuesto sobre el valor añadido.

Directiva 2017/2455 de la Comunidad Europea. Directiva 2017/2455 del Consejo, de 5 de diciembre de 2017, por la que se modifican la Sexta Directiva y la Directiva 2009/132/CE en lo referente a determinadas obligaciones respecto del impuesto sobre el valor añadido para las prestaciones de servicios y la venta a distancia de bienes.

Ley 30264 . Ley que establece medidas para promover el crecimiento económico. Diario Oficial El Peruano, 11 de noviembre de 2014.

Reglamento de Ejecución de la Unión Europea 282/2011. Reglamento de Ejecución 282/2011 del Consejo, de 15 de marzo de 2011, por el que se establecen disposiciones de aplicación de la Directiva 2006/112/CE relativa al sistema común del impuesto sobre el valor añadido.

Reglamento de Ejecución de la Unión Europea 2017/2454. Reglamento de Ejecución 2017/2454 del Consejo, de 5 de diciembre de 2017, por el que se modifica el Reglamento de la Unión Europea relativo a la cooperación administrativa y la lucha contra el fraude en el ámbito del impuesto al valor añadido.

Reglamento de Ejecución de la Unión Europea 2017/2459. Reglamento de Ejecución 2017/2459 del Consejo, de 5 de diciembre de 2017, por el que se establecen disposiciones de aplicación de la Directiva 2006/112/CE relativa al sistema común del impuesto sobre el valor añadido.

Tribunal Fiscal [Perú]. Resolución 2424-5-2002, 3 de mayo de 2002.

Resolución 04091-3-2003, 16 de julio de 2003.

Resolución 215-4-2009, 9 de enero de 2009.

Resolución 6418-1-2014, 27 de mayo de 2014.

Resolución 00045-8-2018, 4 de enero de 2018.

Sentencia del Tribunal de Justicia de la Unión Europea (C-16/93/08, 1994), 3 de marzo de 1994.

Sentencia del Tribunal de Justicia de la Unión Europea (C-246/08, 2009), 29 de octubre de 2009. 